\title{
HAEMORRHAGIC ENCEPHALITIS AND INTENSIVE MAPHARSIDE TREATMENT
}

\author{
By F. L. LYDON, M.B., B.Ch., B.A.O. \\ Major, R.A.M.C. ; Area Venereologist, Middle East Forces
}

Haemorrhagic encephalitis, a serious and often fatal complication of antisyphilitic arsenical therapy, has been reported from time to time in the literature but cases have been so infrequent that few workers have had the opportunity of studying this condition in its various aspects.

At one centre in five out of fifty-three patients with early syphilis who were treated by a short-term intensive course of mapharside, there developed haemorrhagic encephalitis or, as we prefer to term it, arsenical encephalopathy ; this paper gives a detailed account of the syndrome as observed by us together with the results of our investigations.

In the discussion which follows the case records certain suggestions are put forward with regard both to the therapy for and the pathological basis of this condition ; although conscious of their many shortcomings, we believe that they may be of value to other workers in intensive therapy.

We should like to apologize here for the lack of reference to published works, but facilities for an adequate search of the literature have necessarily been lacking owing to service conditions in the Middle East.

\section{Selection of cases and preliminary investigations}

Cases of early syphilis only, that is cases which had occurred within six months of infection, were considered to be eligible for treatment. A searching enquiry into family and personal history and a general physical examination were carried out in all selected individuals, and special attention was paid to the central nervous system. On all patients a dark-ground examination and Wassermann and Kahn tests were performed before treatment:

The following general laboratory tests were carried out in each case, before treatment. (1) Complete blood count, including differential leucocyte count and total number of platelets. (2) Van den Berg test and icteric index. (3) Urine analysis for abnormal constituents such as albumin, sugar and bile. Urinary examinations were carried out daily and van den Berg and icteric index tests were performed on alternate days. At the end of the course a complete blood count was again made.

\section{Administration of mapharside and auxiliary medication}

Five injections of 0.03 gramme of mapharside in 5 cubic centimetres of doubly distilled sterile water were given intravenously daily at two-hourly intervals for five days, by means of a record syringe. The total dose of mapharside given over five days was therefore 750 milligrams. Here it may be mentioned that a certain number of the cases which were treated had had one or two injections of novostab (neoarsphenamine) prior to the commencement of the course ; in not any case was more than 0.75 gramme given. It was of interest to find that these cases appeared to be less disturbed by the course than were those who had not received such preliminary arsenical injections. We accounted for this by postulating that the usual Herxheimer reaction had completely passed away before the intensive course was instituted.

Glucose in large quantities was administered daily and in addition each patient received 200 milligrams per day of ascorbic acid. Mist. acid acetylsal. (aspirin mixture) was used if headache was severe or if the temperature rose to $103^{\circ} \mathrm{F}$. Four-hourly temperature and pulse charts were kept and careful physical examinations were made often, with special reference to the central nervous system. General nursing, with attention to bowels, fluid intake and so,forth was in the hands of a specially selected nursing orderly.

Modification of routine.-As the result of the experience gained after the first three cases of encephalopathy, the following modifications were introduced as 
additional safeguards. (1) Administration of vitamin $B_{1}$. Marmite which contains this vitamin was added to the diet of each patient for five days before treatment and one cubic centimetre of thiamin chloride was given intramuscularly daily for the first three days of treatment. Owing to circumstances beyond our control the next series of patients received one cubic centimetre of thiamin hydrochloride on the morning of the fourth day only. The last group however received the three doses. (2) Lumbar puncture. Lumbar puncture was performed on eight patients on the morning of the fourth day of treatment and the fluid was examined for total protein, Pandy test, cells, sugar and chlorides. (3) Prolongation of the days of treatment to six, with reduction of the number of injections to four daily ; each injection was of 0.04 gramme of mapharside in 6 cubic centimetres of doubly distilled sterile water, that is to say the total dosage of mapharside for the course was 720 milligrams. (4) Three patients in the last group who were undergoing intensive mapharside therapy had blood sugar estimations carried out on the first and fourth day of treatment. The blood for these estimations was collected (a) 45 minutes before the first injection of the day and (b) 15 minutes after each injection throughout the day. The values obtained showed that there was no tendency towards hypoglycaemia in the three patients after repeated injections of mapharside.

\section{General remarks}

Before the case histories of the patients in whom encephalopathy developed are given, certain general observations made by us on those undergoing intensive therapy should be made. As recorded by others, minor complications, for example headache, primary and secondary fever, nausea and vomiting, were common. Primary fever is in our opinion merely a Herxheimer effect since it was absent in a number of patients who had received one or two injections of novostab before the course commenced.

The significance of secondary fever is not understood but its occurrence is in our opinion of little moment, since many of the cases showed this complication but completed the course without mishap. The occurrence of headache always called for vigilance but review of our cases shows that as a warning sign of encephalopathy it is of little value, since many cases with pronounced cephalgia, which sometimes increased as treatment progressed, completed the course without any other complication. Nausea and vomiting were rarely severe and usually disappeared within the first few days and, except for two cases in which a slight general macular rash developed on the last day of treatment, other complications were not encountered.

My general impression on looking back at the series is that all the patients were fit and well in spite of the fact that at times it was difficult to enforce the strict bed routine ordered in all cases.

One observation concerning the drug, mapharside, may be made. It was noticed on one occasion that a very rapid colour change (clear to light brownishyellow) occurred in the solution within 5-10 minutes. Experiments were immediately carried out on several cartons of our stock of mapharside. One ampoule was removed from each carton and dissolved in distilled water. The several solutions were then divided into two parts ; one part was left at room temperature and the other was placed in the refrigerator. The ampoules at room temperature showed the change rapidly (in from fifteen minutes to two hours) whereas those in the refrigerator showed very little change after twenty-four hours. Although we were assured by the manufacturer that this colour change is not accompanied by increased toxicity, we think that during both transportation and storage of the drug in and to tropical and sub-tropical regions, refrigeration conditions are indicated since, although there is not any change in toxicity, there may be some appreciable loss in therapeutic efficiency.

\section{CASE RECORDS}

Case 1.-The patient, aged 23 years, was admitted to hospital with a frenal sore. Spirochaeta 
pallida found. Wassermann and Kahn tests negative. Family and personal history good. Physical examination and laboratory tests showed nothing abnormal.

2.3.42. An intensive course was commenced. Nothing untoward was observed until two hours after the first injection on 5.3.42 (the morning of the fourth day and after 480 milligrams of mapharside had been given). It was then noticed that a very slight delay in answering questions was present but a complete physical examination revealed nothing abnormal and the patient insisted that he felt perfectly well. The second injection was given but before the third injestion the same delay in answering questions was noted. Oral fetor of a peculiar quality was observed ; the pupils were widely dilated equallv but reacted normally. Complete physical examination showed nothing to be amiss. We decided however to discontinue treatment, much to the annoyance of the patient who persisted in saying he was quite well. Constipation, which had been present since the previous day, had been unrelieved by cathartics and now no result followed the administration of an enema. Repeated examination later that afternoon and evening showed no other abnormalities except slight depression, which was attributed to the interruption of his treatment. The following morning (6.3.42) I was informed that he had had a good night, had slept well and in fact was still sleeping. Examination, however, revealed distinct mental apathy with tendency to stupor, speech and cerebration distinctly slowed, oral fetor much more pronounced, pupils dilated equally but reacting sluggishly ; constipation was still present. There was not any neck rigidity, plantar responses were flexor, Kernig's sign was absent, all other reflexes were present and normal. Blood picture, including platelet count, normal. Urine did not contain any abnormal constituents. Lumbar puncture was performed with the following results : clear fluid ; Pandy, strong positive ; protein, 120 milligrams per 100 cubic centimetres ; cellular count below 5 per cubic centimetre ; sugar and chlorides normal. Spinal puncture was repeated again on this day and 15 cubic centimetres of clear fluid were removed with similar reactions. It was noted that speech and cerebration seemed to be quicker after this operation.

7.3.42. Venesection : 17 ozs. of blood removed. Patient mentally confused and restless. Still constipated in spite of cathartics. Marked oral fetor.

10.3.42. Mental confusion less marked but restlessness still present ; obstinate constipation relieved by croton oil. Breath still fetid, speech thick and of a drunken character. All reflexes normal.

- The subsequent course of this case was that of the patient's slow and gradual recovery to the normal. Reflexes tended to become more brisk and for a few days jaw clonus was present. The only other feature noted during the recovery phase was a lack of emotional control ; quite simple questions led to a fit of uncontrolled laughter. An evening temperature of about $99^{\circ} \mathrm{F}$. was noted for about two weeks.

21.3.42. Lumbar puncture was performed with the following results : clear fluid ; protein, 60 milligrams per 100 cubic centimetres ; Pandy, negative ; cells, sugar and chlorides normal.

The slow improvement was maintained and the patient was discharged from hospital on 30.4.42, with a slight degree of ataxia which however disappeared at a later stage. Patient regraded $A 1$ at the end of six months.

Case 2.-The patient, aged 23 years, was admitted to hospital with a large indurated sore in which Spirochaeta pallida were found. Wassermann and Kahn tests were negative. The family history was good. There was nothing unusual in the personal history except that early in 1941 he had had otitis media. Examination showed that there was a dry perforation of the right drum which caused slight deafness. Nothing abnormal was found in the other systems. All laboratory tests gave normal findings.

11.3.42. An intensive course was commenced. The first few days were uneventful, but at 8 a.m. on the morning of the fourth day (14.3.42), after a total of 450 milligrams of mapharside had been given, the patient appeared to be somewhat restless and anxious. It was therefore decided not to give him the first injection on that day as the possibility of encephalopathy was suspected. At 10 a.m. he was seized by a fit of acute anxiety which led to efforts on his part to hide underneath the blankets and he shouted to be taken away from the ward. When he was asked why he was frightened he could only say: "I don't know, please get me away from here, I am frightened to death." Asked especially if he was seeing or hearing anything that was frightening him, he said : " $O$ Oh no, no, I am just frightened and I don't know why." The look of abject fear in his eyes was so intense that he was removed forthwith to another ward and physical examination was carried out, with the following findings. Pupils were widely dilated but reacting normally, breath had a peculiar fetor as in Case 1 . Constipation was again a feature and had been present for 24 hours. The temperature was normal and the pulse rate was 94 per minute. Kernig's sign was absent. All reflexes, superficial and deep, were present and normal. Lumbar puncture was performed with the following results : clear fluid ; Pandy, strong positive ; protein, 360 milligrams per 100 cubic centimetres; cellular content, sugar and chlorides, no change. When examined at 6 p.m. the patient was quiet but apathetic. Incontinence of urine was present ; enemas had failed to relieve the constipation. Examination of the central nervous system revealed nothing abnormal.

15.3.42. Patient still quiet but more apathetic than on the previous evening. Urinary incontinence still present ; pulse irregular and of poor volume. All reflexes present and normal. Bilateral nystagmus noted. At 7 p.m. the patient became unconscious and convulsions supervened at 11.55 p.m. He died at 2 a.m. on 16.3.42.

Treatment had been on the same general lines as in the previous case-venesection, lumbar puncture, adrenaline-but in this case they were unfortunately of no avail. 
Case 3.- The patient, aged 24 years, was admitted to hospital with a large sore on the glans penis in which Spirochaeta pallida were found. Wassermann +++ and $\mathrm{Kahn}+++$. There was a large bubo in the right groin. Family history and personal history were good. Physical examination and laboratory reports did not show anything abnormal. Prior to the intensive course he had received 0.75 gramme of novostab intravenously. The patient, on learning that he had contracted syphilis, asked innumerable questions at every opportunity about the possibility of cure for his condition. This anxiety or preoccupation persisted for the first two days of treatment, but by the third day his interest shifted from himself to the reaction of his fellow patients and he appeared to be normal. On the morning of the fourth day (3.5.42), however, a slight tinge of anxiety was again present; it was now accompanied by an "alertness " or " watchfulness.", Physical examination revealed nothing abnormal with the exception of a (doubtful) left extensor plantar response. Treatment was discontinued as encephalitis was suspected. At 5 p.m. there was a dramatic onset of tremor with great excitability and apprehension. The patient shouted: "I am going to die. Get me out of here. I am dying." He made violent efforts to get out of bed and was restrained with difficulty. Although obviously still very excitable and frightened it was possible to examine him a little later. with the following findings. Pupils were widely dilated, equal and reacting normally. Oral fetor was present. All reflexes were normal except that there was doubtful extensor plantar response on the left side and difficulty in eliciting left lower abdominal reflex. Constipation had been present for the past 24 hours. Lumbar puncture gave results as follows : clear fluid ; protein, 120 milligrams per 100 cubic centimetres ; Pandy, positive ; no change in cellular contents, chlorides or sugar.

4.5.42. Still excited and apprehensive. No evidence of either visual or auditory hallucination. Breath showed peculiar fetor noted in the other cases. Constipation still present and unrelieved by enema. All tendon reflexes present and normal. Blood pressure 124/80. Blood count, including platelets, normal. Pressure test for capillary fragility negative. Lumbar puncture gave : clear fluid ; protein, 240 milligrams per 100 cubic centimetres; Pandy, strong positive ; cells, 350 , mostly erythrocytes.

6.5.42. Patient showed no change but had become quieter. Abnormalities not discovered on physical examination. Lumbar puncture gave : clear fluid under pressure; protein, 240 milligrams per 100 cubic centimetres ; Pandy, strong positive ; no change in cellular contents, chlorides or sugar.

8.5.42. Patient complained of headache and vomiting, neither being serious. Much more subdued. A bilateral nystagmus present. All reflexes brisk and normal. Blood pressure 112/70. Lumbar puncture gave : protein, 300 milligrams per 100 cubic centimetres; Pandy, positive ; nothing else abnormal.

9.5.42. Marked improvement, no headache, no vomiting. Fetor of breath had now disappeared completely. Reflexes as before. Lumbar puncture gave : protein, 180 milligrams per 100 cubic centimetres ; Pandy, positive ; Wassermann, negative.

17.5.42. General condition good; nothing notable had occurred in the interim. Lumbar puncture gave : protein, 60 milligrams per 100 cubic centimetres; Pandy, doubtful ; nothing else abnormal.

10.6.42. General condition now normal. The patient was seen again a few months later and after a thorough general examination was found to be perfectly fit.

Case 4.-The patient, aged 26 years, was admitted with a large indurated sore in coronal sulcus in which Spirochaeta pallida were found. Bilateral adenopathy. Wassermann, ++++ and $\mathrm{Kahn},++++$. Prior to the course he received 0.75 gramme of neoarsphenamine and 0.2 gramme of bismuth.

16.5.42. An intensive course was commenced. The course was completed without any untoward signs on 21.5.42. One cubic centimetre of thiamin hydrochloride was injected on the morning of the fourth day, and lumbar puncture was performed. (See modification above.)

19.5.42 (morning of fourth day of treatment). Lumbar puncture gave : clear fluid ; protein, 40 milligrams per 100 cubic centimetres ; Pandy, negative ; no change in cell contents, chlorides or sugar.

21.5.42. At 8.30 p.m. ( $2 \frac{1}{2}$ hours after last injection) the patient complained of vertigo and intermittent amblyopia. Examination showed nothing abnormal. Patient apparently had a good night and slept well.

22.5.42. At 9 a.m. the patient was apathetic ; cerebration was slowed but he answered all questions sensibly. Oral fetor was noticed for the first time and constipation of 24 hours' duration was unrelieved by cathartics. Pupils were dilated equally and reacted normally. Nothing abnormal was discovered on physical examination ; all tendon reflexes were present. Kernig's and Babinski's signs were absent. Lumbar puncture gave : colourless fluid ; protein, 45 milligrams per 100 cubic centimetres ; Pandy, negative ; no change in cellular contents, sugar or chlorides. Blood picture normal, including platelet count. Capillary fragility test negative. Up to 6 p.m. On this day the stupor increased although the patient could still be roused and answered questions intelligently but slowly. Restlessness appeared as the day advanced. Pulse 94, regular and good tension. Temperature 99.8. Two enemas failed to relieve the constipation. Nothing abnormal noted on examination of central nervous system. 1 cubic centimetre of vitamin $B_{1}$ was given intramuscularly and 10 cubic centimetres of calcium gluconate intravenously.

23.5.42. Patient mentally more alert but cerebration still slowed; all tendon reflexes present but sluggish; absence of right upper and lower abdominal reflexes. In addition there was a distinct paresis of right arm and leg, voluntary movement being absent. There was also a marked 
nuchal rigidity, uninfluenced by extension of the leg on the flexed hip. Sensation was normal. Kernig's and Babinski's signs were absent. Bowels had been opened once and that only moderately by an enema which had been retained for nearly 4 hours. Lumbar puncture gave : colourless fluid ; protein, 120 milligrams per 100 cubic centimetres ; Pandy, positive ; no change in cells, sugar or chlorides.

24.5.42. Mental condition much improved but the physical condition and findings of the previous day remained unaltered.

25.5.42. Condition much improved but nuchal rigidity and hemiparesis still present although less noticeable. Between 3.40 and $4.10 \mathrm{p} . \mathrm{m}$. patient had three convulsive attacks during which he lost consciousness. By 4.10 p.m. consciousness was regained and examination did not reveal anything new except a slight nystagmus to the right.

29.5.42. During these four days, the patient had made rapid progress and at the end of this period the nuchal rigidity and hemiparesis had disappeared. Lumbar puncture gave: protein, 70 milligrams per 100 cubic centimetres ; Pandy, negative ; no change in cells, chlorides or sugar. Serial cerebrospinal fluid examination showed continued improvement and on 16.6.42 the findings were : protein, 50 milligrams per 100 cubic centimetres ; Pandy, negative ; no change in cells, sugar or chlorides. The general condition was normal; the only sign noticed was a slight briskness of all reflexes. Treatment of this case consisted of daily injections of 1 cubic centimetre of vitamin $B_{1}$ and calcium gluconate 10 cubic centimetres daily for one week; - except serial lumbar puncture no other treatment was given.

Case 5.-The patient, aged 28 , was admitted to hospital with a large subpreputial ulcer in which Spirochaeta pallida were found. Wassermann and Kahn tests were negative. Family history good. Personal history negative except that he admitted consumption of alcohol to have been very heavy ( $9-12$ bottles of beer per day). One year before admission he was posted to active service where it was impossible for him to get more than his ration of alcohol. Although we questioned the advisability of giving him the course of mapharside it was decided to do so. All laboratory tests and careful clinical examination failed to reveal any abnormality. Injections of vitamin $B_{1}$ were given on the 4th, 5th, 6th and 7th of October 1942.

5.10.42. An intensive course was commenced. Nothing abnormal was noticed until the morning of 8.10.42, when the patient was found to be apprehensive and restless ; he said: "I feel dreadful." He stated that he had been in the lavatory when he heard an aeroplane coming over faurly low. This startled him badly and he returned immediately to his ward. Nothing abnormal was found on general examination. Luminal grain 1 was administered. At $8.50 \mathrm{a.m}$. he suddenly collapsed and lost consciousness ; there were stertorous breathing and cold clammy skin with internal strabismus of the right eye; all reflexes were normal.. Injection of coramine 1 cubic centimetre was followed in about 10 minutes by recovery of consciousness. There ensued a period of about $1 \frac{1}{2}$ hours during which the patient was restless and made several attempts to get out of bed. He was however easily restrained. Vitamin $\mathbf{B}_{1}$ was injected and he appeared to be nearly normal at 10 a.m. except for a slightly dazed appearance. Lumbar puncture was performed at 12 noon and the results were : protein, 320 milligrams per 100 cubic centimetres ; Pandy, strongly positive ; no change in cellular content, sugar or chloride. On the evening of this day the patient appeared to have completely recovered except for some frontal headache ; he was given vitamin $B_{1}, 1$ cubic centimetre subcutaneously.

9.10.42. The patient appeared to be normal except that he had a slightly dazed look and was perhaps a little slow in answering questions. Clinical examination revealed nothing abnormal. Blood count was normal, including platelet count. Capillary fragility test was negative. Treatment was continued for 4 days more by daily injections of vitamin $B_{1}$ and 10 cubic centimetres of calcium gluconate.

29.10.42. Nothing untoward occurred up to this time and patient was discharged from hospital. He was readmitted on 18.11.42 for examination of the cerebrospinal fluid. Lumbar puncture then gave : protein, 50 milligrams per 100 cubic centimetres ; Pandy, negative ; cells, sugar, and chlorides, no change.

\section{POST-MORTEM REPORT ON CASE 2}

(By Capt. Morgan, R.A.M.C.)

Liver, spleen, heart, kidneys, brain and spinal cord submitted for histological examination. The arsenical content of hair and nails, together with that of the above organs, to be estimated. Death following treatment with mapharside.

\section{Macroscopic}

Brain and cord.-Superficially the brain shows no abnormality on coronal section of the cerebral hemispheres at the level of the midbrain; haemorrhages about 1 inch long and about inch thick are observed in each external capsule just below the surface of the island of Reil. Scattered haemorrhages are observed in the corpus callosum. In the mid portion of the left hippocampus major is a haemorrhage, about $1 \times 0.5$ centimetre, which bulges into the posterior horn of the lateral ventricle. The main haemorrhage is in the pons which is almost completely destroyed by multiple haemorrhages from the pontine vessels. Upward extensions of this area are seen in the midline of the midbrain. The medulla, cerebellum and spinal cord on section show no naked-eye abnormalities.

Spleen.-Firm and slightly enlarged. Nothing abnormal to note on section.

Liver.-Does not show anything of pathological interest. 
Kidneys.-Dark and congested.

Arsenical content.-(Public Health Laboratory analysis).

$\begin{array}{lll}\text { Brain } \quad \ldots & 0.017 \text { milligram per } 100 \text { grammes }\end{array}$

Kidney $\quad \ldots \quad 0.050$ milligram per 100 grammes

$\begin{array}{llll}\text { Liver } & \ldots & 0.075 \text { milligram per } 100 \text { grammes }\end{array}$

Spleen $\quad \ldots \quad 0.15$ milligram per 100 grammes

Heart $\quad \ldots \quad 0.025$ milligram per 100 grammes

Hair $\quad \ldots \quad 0.004$ milligram per 100 grammes

Nails $\quad . . \quad$ Unmeasurable trace

\section{Histopathology}

Cerebral cortex.-The meninges are normal, the pyramidal cells are unimpaired and the white matter does not show anything of note.

External capsule.- The arterioles are congested and one or two show a narrow layer of perivascular lymphocytes and polymorphs, the latter predominant. The haemorrhagic area seen macroscopically proves to be formed by a large number of capillary haemorrhages with destruction of the white matter. The nerve cells of the claustrum show degenerative changes.

Basal ganglia.- The nuclei themselves do not show any notable changes. The neuroglia underlying the ependyma of the lateral ventricles is oedematous and shows an increase in microglial cells. The vessels. are very congested and there is a great increase in the Virchow-Robin's spaces but haemorrhage is not a feature.

Hippocampus.- The haemorrhage referred to above has caused local destruction and disorganization of the grey matter. The hippocampal nerve cells show degenerative changes in nuclei and cytoplasm but the cells in the neighbouring dentate convolution appear to be healthy. A careful search was made for Negri bodies in hippocampus and cerebellum by means of Leishmann-stained tissues, with negative results.

Midbrain.-Multiple haemorrhages are observed along the line of central decussation. The vessels are congested and some show perivascular infiltration with polymorphs. The nerve cells near the midline are very degenerate.

Cerebellum.-The morphology of the Purkinje cells is preserved but some show eosinophilic staining of the cytoplasm. The white matter shows congestion of vessels, perivascular haemorrhage and perivascular infiltration with polymorphs.

Pons.- Numerous haemorrhages are observed throughout from large and small vessels which have caused widespread destruction of nerve fibres. Many nerve cells in the vicinity show degenerative changes.

Medulla.-Extreme degeneration has occurred in the olivary bodies, the cells being pyknotic and shrunken. In many places they have disappeared altogether and have left a row of tiny cyst-like spaces along the line of the olivary bodies. Haemorrhage is not a feature.

Spinal cord.- Sections at different levels do not show anything of note in the meninges or in the grey or white matter.

Liver.-There is great dilatation of the capillary sinuses, although most of the erythrocytes seem to have been eliminated. The columns of the liver cells are correspondingly shrunken towards the centre of the lobules and the total number of liver cells in the central zone is distinctly reduced.

Heart and spleen.-Not any notable changes.

\section{Discussion of post-mortem findings}

The picture is that of an acute haemorrhagic encephalitis. Possibly " encephalopathy", would be a better term as the signs of inflammation are subordinate to the haemorrhages. I am unable to find any reference to such a condition as a complication of chronic arsenical poisoning in the text-books at our disposal, but in a series of brains sent to the Central Pathological Laboratory last year two of the patients had died from encephalitis while under treatment for syphilis.

(1) The first patient had had 4 injections of sulphostab (sulpharsphenamine) and 3 of bismostab (metallic bismuth), followed by 6 injections (unspecified), all over a period of 2 months. Chronic diarrhoea and a rash then developed, and he eventually died of encephalitis of a slowly progressive type. Histologically, multiple perivascular haemorrhages were observed but not any perivascular cellular infiltration.

(2) The second patient was " under treatment for syphilis", A fulminating encephalitis developed with spastic muscles and he died within 20 hours. His brain showed both haemorrhages and perivascular cellular infiltration.

In neither case however were the changes in the nerve cells particularly severe. The number of troops who receive arsenical treatment is probably fairly large and it remains to be proved that arsenicals cause the encephalitis ; on the other hand fatal cases of encephalitis are relatively common.

The great majority of brains sent here have been straightforward cases of polioencephalitis. of the small number of equivocal cases this is the third time in which antisyphilitic treatment has been a possible predisposing factor although the clinical course, amount of drug given and so forth have been variable.

\section{DISCUSSION}

Literature on haemorrhagic encephalitis available to us in the Middle East is 


.

very scanty, but Moore, quoting Schamberg and Wright, gives the following description.

"The clinical picture of haemorrhagic encephalitis is a fairly constant one, and is prone to
develop after relatively few injections of an arsenical compound. After the second, third
or fourth injection there is commonly a moderate febrile reaction which may fall to normal.
Two or three days later the patient complains of headache, sometimes associated with
nervousness and apprehension. Cephalgia increases and the first alarming symptom may
be a convulsion which may be preceded by apathy and mental confusion. Death commonly
takes place 24 to 48 hours after the onset of the symptoms. The characteristic pathological
feature of the condition consists of oedema of the brain with multiple punctate haemorrhages
(ring) and areas of focal necrosis. There is no tendency to haemorrhage elsewhere in the
body and pathological changes noted in the other organs are decreed unimportant. No
theory so far appears to offer an explanation of the condition."

The treatment advised is repeated lumbar puncture if the pressure is high, venesection, purging and large doses of sodium bicarbonate. Special attention is drawn by Stokes to adrenaline, and in this connexion he stresses its value and advises that doses should be given as long as improvement continues. It has been impossible for us to study any post-mortem pathological reports, but Hahn in a review apparently insists that the presence of haemorrhages and focal necrosis are essential to the diagnosis post mortem.

If we now contrast the signs and symptoms as outlined above with those in our group, we find that there are certain marked differences of great importance. First, the primary signs of encephalopathy in our cases occurred in the mental sphere either as a sudden explosive onset of acute apprehension and fear, unaccompanied by visual or auditory hallucination, or as a general slowing of cerebration.

It is perhaps as well here to insist that in the latter type of onset the lag and apparent indifference in answering questions is very slight in the early stages and, in fact, is rather reminiscent of the behaviour of one who is asked a question whilst he is reading an interesting book. In order that it should be recognized early, therefore, some knowledge of the normal reaction of the patient is necessary if the change is to be noted. In the apprehensive type the change is so sudden and violent that at first sight it would appear that these early changes are not present, but we think that here too slight increases in apprehension are likely to be misinterpreted and put down to the trying repetition of intravenous injections. These slight behaviour changes are in our opinion of great value, because they not only serve as danger signals but also suggest that the primary pathological change may be in the brain tissue itself. This latter point will be reverted to later in the discussion when the pathological aspect of the condition is under review. The only other signs of early import noticed were oral fetor of a distinctive kind, obstinate constipation and widely dilated pupils, equal and reacting normally. Headache, although present, is in no way characteristic-a point already made in our general remarks above. Convulsions may occur but they are usually a later manifestation and of serious prognostic import.

Kernig's sign.-Kernig's sign was absent in all our cases and, since meningeal involvement is not a feature of haemorrhagic encephalitis, one would expect this sign to be absent. We therefore suggest that in the cases in the literature in which Kernig's sign was reported to be present the condition was really one of nuchal rigidity, as described in our Case 4.

Babinski's sign.-This sign was observed as a " doubtful " unilateral response twice in our cases. In Case 1 an observer described this response, but neither before that occasion nor subsequently were we able to elicit a like response. In Case 3 it is noted that during the morning of the fourth day of treatment an indefinite extensor response was observed on the left side but was never again observed throughout the rest of the illness. The presence of an extensor response is conceivable, for as it is dependent upon the pyramidal tracts these latter may be affected (1) by oedema leading to interference with conductivity-in this case the sign would presumably disappear with the removal of the oedema-and (2) by gross haemorrhage causing interruption of the tract-in this case the sign would persist. 
It has been suggested by some that haemorrhagic encephalitis may be merely coincidental and not in any way due to the administration of arsenic itself. Capt. Morgan mentioned this point in the post-mortem report on Case 2. Whereas it may account for some cases labelled haemorrhagic encephalitis, we consider that the bulk of evidence favours the intimate aetiological relation of the arsenicals. How these drugs bring about the condition and what tissue is primarily affected are points of practical importance, since prophylaxis and therapy depend upon a proper appreciation of this problem. The widely accepted vasculotoxic effect of the arsenicals at first focuses our attention on the capillaries as the site of the primary damage. However, the fact that there is no evidence of capillary change elsewhere in the body is difficult to correlate with this view, except either by postulating a selective action of the arsenicals on the cerebral vessels or by assuming that widespread capillary change is present throughout the body, but is of such a type that the ill-supported vessels of the brain show evidence of the change long before it is sufficiently advanced to affect those of the other tissues. Again, absence of any alteration in the blood platelet count, together with the negative pressure tests obtained in our cases, tends to eliminate the capillaries as being the seat of the primary pathological process.

Hahn, as stated above, insists on haemorrhage and focal necrosis, post mortem, to establish the diagnosis, but cases have been recorded by competent observers in which oedema and capillary congestion were the only cerebral changes noted. It therefore seems to us that the post-mortem changes of haemorrhage and focal necrosis are merely advanced stages of a pre-existing pathological condition of oedema and congestion. This contention is supported by a reviewer of Hahn's article in the British Journal of Hygiene.

The above facts, combined with the early disorder of cerebration noted by us, turned our attention to the possibility that the brain tissue itself may be primarily affected. If some interference with normal cellular metabolism were to be postulated the following scheme appeared to be theoretically sound: (1) interference with cellular metabolism, (2) accumulation of metabolites within the cell, (3) increased retention of fluids by cell-oedema of tissue, (4) interference with normal capillary circulation, (5) congestion and (6) haemorrhage and focal necrosis.

The interference with cellular metabolism suggested above may be directly due to the arsenicals themselves. Otherwise, as is more likely in our opinion, the administration of arsenic calls for excess of some other factor necessary for efficient cellular metabolism ; this factor would be supplied exogenously through the food or elaborated endogenously within the body by some organ-perhaps by the liver. If this interpretation is accepted, the fact that the cerebral tissues are so highly developed explains the early involvement of the brain before evidence is observed in the other organs. At this stage it should also be noted that in the post-mortem report on Case 2 extensive damage is reported to have been found in the liver; whatever significance is attached to this finding we consider that there is little doubt that it is part of the general pathology of the condition.

In order to try to find a clue to guide us before we submitted any more cases to the intensive mapharside course, a critical review of all known factors was carried out after Case 3 had occurred. The inability of laboratory tests or of repeated clinical examination to afford any information about the onset of encephalopathy focused our attention on the behaviourisms outlined in the case histories. The resemblance of these mental changes to those of the two types of alcoholism - that is the apprehensive to that of delirium tremens and the stuporous to that of chronic alcoholism-led us to make the tentative suggestion that perhaps a similar pathological condition was present. As an expansion of this original premise, the following points were tabulated :

(1) Stokes, quoting Lees, states that alcoholism has been the only predisposing factor.

(Compare with vitamin $\mathbf{B}_{1}$ deficiency.)

(2) Predilection of alcohol and arsenic for certain body tissues such as liver, brain and nerves.

(3) The pathological basis of delirium tremens has been ascribed to oedema of the brain, 
whereas in Korsakoff's syndrome areas of punctate haemorrhage have been found post mortem. (Note here the therapeutic value of vitamin $\mathrm{B}_{1}$ in delirium tremens.)

(4) Wernicke's encephalopathy. This syndrome has been ascribed to vitamin $B_{1}$ deficiency and arises in cases in which absorption is interfered with, for example in gastrectomy and in gastric carcinoma. Post-mortem punctate haemorrhage and necrosis have been found especially in corpora mamillary bodies and along the midline of the brain. Alexander in discussing these post-mortem changes postulates the presence in vitamin $B_{1}$ of an antiangiodegenerative factor.

(5) The experimental effects of vitamin $B_{1}$ deficiency in pigeons (Samson Wright) : (a) polyneuritis with good health; (b) polyneuritis with ill health; (c) fulminating cases which show great prostration. Head retraction is very often seen in these experimental birds and administration of vitamin $B_{1}$ brings about a dramatic and rapid improvement in type (c). The other types improve only slowly under vitamin $B_{1}$ therapy.

(6) Vitamin $B_{1}$ is intimately associated with the metabolism of carbohydrate, especially in the brain. It is said that this vitamin is essential for the metabolism of carbohydrate at its ' pyruvic acid' stage, since deficiency leads to an increase of the acid in the circulating blood, and that this increase disappears on the addition of vitamin $B_{1}$. The important part played by carbohydrate metabolism in cell respiration is well known.

(7) Hahn, in discussing liver atrophy after arsenical treatment, states that deficiency of vitamin $B_{1}$ has been suggested as an important factor in its aetiology.

It seemed to us from the foregoing that vitamin $B_{1}$ might be an additional safeguard, especially if checked by a lumbar puncture on the morning of the fourth day. A new group was therefore placed on intensive therapy, with modifications as outlined above, with the result that in one case(Case 4)encephalopathy developed $2 \frac{1}{2}$ hours after the termination of the treatment on the sixth day. The dramatic therapeutic effect of vitamin $B_{1}$ in this case-the patient was returned category Al within three weeks - together with the later onset of the complication and the fact that it was possible to give him only one injection of thiamin hydrochloride, seemed to us to be sufficient warrant for another trial. A new group was started, but again encephalopathy developed in one patient, this time on the morning of the fourth day (Case 5). This case seemed at first sight to refute our theory of the value of vitamin $B_{1}$ but review of all the known factors raised several important points. The patient admitted to heavy indulgence in alcohol up to one year previously. He was then sent to the Western Desert where, although alcohol was scarce, food rich in vitamin $B_{1}$ cannot have been very abundant. The presumed deficiency of vitamin $B_{1}$ from both these factors acting over a long period may have been of such a kind that either we did not give sufficient vitamin $\mathbf{B}_{1}$ (compare Case 4) or the vitamin should have been given for some time previous to the commencement of the intensive course in order to allow the tissues to recover their normal resistance. The therapeutic effect of vitamin $B_{1}$ however again appeared to be of distinct value in this case.

\section{RECAPITULATION}

Five out of fifty-three patients with early syphilis who underwent intensive mapharside therapy developed haemorrhagic encephalitis. The following points are emphasized.

(1) The term, haemorrhagic encephalitis, should be replaced by the term, arsenical encephalopathy, since neither haemorrhage nor inflammation are necessarily pathological features.

(2) Arsenical encephalopathy can be definẻd as an acute cerebral complication which occurs during arsenical therapy and is characterized clinically in its early stages by changes in the mental sphere which are of two distinct types, (a) lethargic and (b) apprehensive.

The onset is accompanied by distinct changes in the cerebrospinal fluid, namely increased protein, positive Pandy test without any increase in cellular elements and no change in sugar or chloride contents. The early recognition of these mental changes is of paramount importance both for cessation of the arsenical drug and for institution of treatment.

Associated with the preceding are often oral fetor of a characteristic type, widely dilated pupils, equal and reacting normally, and constipation of a particularly obstinate nature. Fever and headache although present are in no way typical and general examination of the central nervous system shows nothing abnormal.

At a later stage various signs make their appearance, for example emotional instability, perseveration, paresis, nystagmus ; this merely indicates that the pathological process is very widespread. A slight but persistent rise of evening temperature (about $99^{\circ} \mathrm{F}$.) was noted for about two weeks in some of our cases. Convulsions may occur, usually within the first few days ; they are of serious import and probably indicate haemorrhage into the brain substance. Reversal of cerebrospinal fluid changes occurs slowly; the Pandy test 
first becomes negative, and is followed later by a fall of the protein value to the normal. In Case 3 it will be noted that a large increase of cells occurred after one puncture, but we are of the opinion that this resulted from the introduction of blood by a faulty puncture, and was not indicative of blood in the cerebrospinal fluid, since the next puncture gave the expected reading, that is to say, no increase in cellular elements.

(3) Alcoholism (as noted by Lees) is again suggested as a predisposing factor and to this is added those cases in which deficiency of vitamin $B_{1}$ is to be expected.

(4) Vitamin $B_{1}$ is suggested as both a prophylactic and a therapeutic agent ; calcium gluconate is also used as an adjunct. Venesection, repeated lumbar puncture and adrenaline seem to be of value.

(5) Help in foreseeing the onset of encephalopathy is not obtained from the usual laboratory tests made either before or during treatment. It is advisable however that they should be still carried out since they give information about the patient's general condition.

(6) From the pathological point of view, the possibility of primary cellular damage of the brain tissue itself is put forward in place of the more usually accepted vasculo-toxic theory. We feel that vitamin $B_{1}$ deficiency and the liver disorder play important parts in the production of the damage and in this connexion attention is drawn to the noticeable microscopical changes found in the liver in our fatal case.

(7) Blood sugar curves taken during the intensive course in three patients did not show any tendency towards hypoglycaemia during treatment and lumbar puncture performed on the fourth morning did not show any change in the cerebrospinal fluid in eight patients, although in one encephalopathy subsequently developed on the evening of the sixth day.

(8) In tropical climates mapharside undergoes a rapid colour change which, although not associated with increased toxicity, may be associated with a loss of therapeutic efficiency and therefore, during transit and storage, it should be kept in cold conditions.

\section{CONCLUSIONS}

From our own small experience and from perusal of the available literature on intensive mapharside therapy, encephalopathy appears to occur many times more often under this method than under the various long-term schemes of antisyphilitic treatment, whereas exfoliative dermatitis, liver atrophy and the other serious toxaemias show no such increased incidence. Therefore, apart from the cure of syphilis, it is necessary to carry out extensive research into the causation and treatment of encephalopathy before the intensive method can be applied generally. If it is admitted that in this paper a case has been made for the part played by vitamin $\mathbf{B}_{1}$, the following points may be of additional interest to other workers in the intensive field.

(1) What effect on the incidence of encephalopathy have pregnancy and the toxaemias of pregnancy in women undergoing antisyphilitic therapy, either by the long-term or the short-term method?

(2) Is it possible that the other constituents of the vitamin B complex also play a part ? (Note here that riboflavin has an important influence on intracellular metabolism and that nicotinic acid is believed by some to exert a protective action in other chemical liver toxaemias.)

(3) Beri-beri and pellagra. These two diseases are intimately concerned with vitamin B deficiency and consideration of their various clinical pictures brings out some interesting features, as follows. (a) Fulminating fatal cases have been described. It would be interesting to know whether or not perivascular haemorrhage or cerebral oedema was a feature post mortem. (b) There is a tendency to oedema of the tissues in the wet type of beri-beri. (Compare the alarming rapidity with which fatal cardiac oedema occurs.) (c) The post-mortem changes in the central nervous system, in. both diseases, are held by some observers to depend upon the same aetiological causes as do those found in Korsakoff's syndrome, in central neuritis and in subacute combined degeneration of the cord. Although these changes on the surface bear no resemblance to those found in encephalopathy, it should be remembered that pathological appearances due to the same aetiological causes may vary enormously both with the acuteness of the process and with the time during which the changes occur. (d) Pyruvic acid has been found to be increased in the urine, blood and cerebrospinal fluid, in cases of beri-beri. Estimation of pyruvic acid in these fluids may be of value therefore in patients who are about to undergo and who are undergoing intensive mapharside therapy. (e) As indicated in the text, Hahn suggests an important

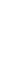


part for vitamin $B_{1}$ deficiency in producing the liver atrophy which occurs during arsenical treatment. It is possible that the same factors of arsenic and vitamin $B_{1}$ deficiency may bring about the other serious arsenical toxaemias by affecting other tissues, for instance skin or bone marrow.

The intensive treatment was carried out under the direction of Brig. R. Lees, Consultant Venereologist, M.E.F., whose help and guidance is gratefully acknowledged.

Thanks are due to Major A. L. Williams, Capt. A. D. S. Cameron, Capt. W. R. S. Cowe and Capt. F. Lancely, R.A.M.C., who assisted at various times during the period of treatment ; to Major Cook and Major Amies, R.A.M.C., for pathological investigation ; to Capt. Morgan, R.A.M.C., for his excellent post-mortem report in Case 2 ; finally to Major C. Vaillant, R.A.M.C., for his cooperation in the medical care of the cases of encephalopathy which developed. Without their help this work would have been impossible.

\title{
SULPHONAMIDE THERAPY OF GONORRHOEA IN THE MALE
}

\section{REVIEW OF FOUR YEARS' EXPERIENCE*}

\author{
By D. I. WILliAMS, Maj. R.A.M.C., A. J. KING, Lt.-col. R.A.M.C., and \\ C. S. NICOL, Maj. R.A.M.C.
}

The unrestrained ardour and enthusiasm which inevitably hamper assessment of the power of new and valuable remedies-and which only restriction of supply has prevented from engulfing early judgment of the new drug, penicillin-have become a matter of ancient history with regard to the sulphonamide therapy of gonorrhoea. Early claims of success in 90 to 100 per cent of cases, often based on very small experience, have been relegated to the forgotten and forgiven past.

\section{Early work with sulphonamides}

The extensive literature which has accumulated on this subject makes a full survey impossible. It is of interest however to quote the experiences in the last five years of some workers in Great Britain who have recorded their results from the use of sulphapyridine.

In 1939 at a meeting of this Society Cokkinis claimed that 77 per cent of cases treated in the first week of the disease and 85 per cent treated in the second week were cured, with a late relapse rate of 9 per cent. At the same meeting one of us (King) claimed that in over 90 per cent of 300 cases signs and symptoms had disappeared in less than three weeks. 250 of these cases had irrigations of the posterior urethra, which did not materially affect the results.

In 1940 Prebble gave his results in two series of cases. In the first series, 65 cases were treated with 3 grammes of sulphapyridine daily for 6 days with a cure rate of 57 per cent. A second series of 246 cases was treated with 3 grammes daily for 7 days and $1 \frac{1}{2}$ grammes daily for 7 days, with irrigations in most cases. Of these there was " real cure"' in 66.4 per cent and "apparent cure"' in 24 per cent. Mackinnon in the same year stated that the following scheme of treatment was likely, to give a 100 per cent rate of cure. In the first week 1.5 grammes were given daily with urethral irrigations ; in the second week 0.75 gramme daily with urethral irrigations and in the third week urethral irrigations only. He admitted a 5.5 per cent relapse rate after provocation.

Sommerville in 1941 treated 300 cases with 2 grammes daily for 7 days followed by irrigations for 2 weeks. There were only 2 failures $(0.7$ per cent) and relapse in 6.7 per cent. He considered that these results served to prove his contention that large doses of the drug were not necessary-with all due deference to those who believed in and employed massive or intensive dosage. MacKenna gave 22 grammes in 48 hours followed by irrigations for 3 days. He quotes no immediate failures, but admits less than 5 per cent of late relapses.

\footnotetext{
*A paper read to the Medical Society for the Study of Venereal Diseases, 29th April, 1944.
} 